Original article

\title{
Factors affecting External causes of deaths among adults (15-59 years) in South Indian states: A study using Bayesian model on National Family Health Survey-4 (2015-16) data
}

\author{
Apyayee Sil $^{\mathrm{b}}$, Arpan Sil ${ }^{\mathrm{a}}$, Preeti Dhillon ${ }^{\mathrm{b}}$, Mithun Mog ${ }^{\mathrm{c}, *}$ \\ ${ }^{a}$ Symbiosis Statistical Institute, Symbiosis International (Deemed University) SSI, A 106, ICC Trade Tower 403A, International Convention Centre, Senapati Bapat Road, \\ Pune, Maharashtra-411016, India \\ b Dept. of Mathematical Demography and Statistics, International Institute for Population Sciences (IIPS) Govandi Station Road, Deonar, Mumbai, Maharashtra-400088, \\ India \\ ${ }^{\mathrm{c}}$ Department of Management, Humanities \& Social Sciences, National Institute of Technology, Agartala,799046, Tripura, India
}

\section{A R T I C L E I N F O}

\section{Keywords:}

Adult deaths

Bayesian methodology

External deaths, unnatural deaths

South indian states

\begin{abstract}
A B S T R A C T
The study aimed at finding risk factors associated with adult mortality (15-59 years) due to external causes (accidents, suicide, poisoning, homicide, and violence) of the South Indian states by using the fourth round of National Family Health Survey data. Despite having a higher literacy rate and comparatively being better developed than other Indian states, the number of external causes of deaths in the South Indian states is alarming. The study used Bayesian Logistic Regression method for analysis. Three Chain of Markov Chain and Monte Carlo (MCMC) model was used. The sex of the deceased was found to be an important factor in all 5 states (Tamil Nadu, Karnataka, Kerala, Tamil Nadu, Telangana and Andhra Pradesh). Place of residence was an important factor for all states except Karnataka. The prevalence of external adult deaths was high among femaleheaded households irrespective of all the south Indian states. The family members in Karnataka and Andhra Pradesh, wealth index in Telangana, drinking habit in Kerala, car access in Kerala and Tamil Nadu and massmedia access in Tamil Nadu were found significant factors (the model converged for the factors) that affecting external causes of deaths. Some holistic efforts should be undertaken by the Government for adult deaths by spreading awareness among adult, setting up specialized teams for policy-making and timely measures to curtail the underlying causes of such unnatural deaths and to ameliorate the overall situation.
\end{abstract}

\section{Introduction}

Reducing mortality due to external causes (accidents, violence, homicide, suicide, poisoning) was mentioned in the Third Sustainable Development Goal which focused on promoting wellbeing and ensuring healthy lives. Deaths due to external causes are gaining momentum among adults, creating catastrophic loss of life and affecting society as the premature death of the principal bread-winner often inflicts serious financial hardship upon the family. ${ }^{1}$ Damage to this section of society has a substantial impact on the socio-economic development of a country and also may lead to a slowdown in overall national development. An understanding of levels, trends and patterns of the adult deaths due to external causes along with the determinants, therefore becomes an important part of any demographic inquiry. In this paper, we made an attempt to understand the important factors affecting the external causes of deaths in the Southern states of India. ${ }^{2}$ Inspite of being more developed and having comparatively higher literacy rates (among the country), the number as well as the prevalence of external deaths in these states are alarming.

In terms of suicide rates, 4 of the 6 top Indian states are from South India. It was found that, the South Indian states had higher suicide rates than the National average, with Kerala having the highest suicide rate (27.7 per lakh population) among all the Indian states (Karnataka 20.7/ 100,000, Tamil Nadu 18.6/100,000, and Andhra Pradesh 16.8/ 100,000). ${ }^{3}$ This has been further established in the article "Andhra Pradesh is 3rd on suicide list", ("Andhra Pradesh is 3rd on suicide list", 2010).

Also, deaths owing to suicides and self-harm in the age group 15-39 years in the Southern states was three times higher as compared to the other states of India. Karnataka was recognized as the second safest state

\footnotetext{
* Corresponding author.

E-mail address: mi2un90@gmail.com (M. Mog).
} 
in South India except for its capital Bangalore, which ranked second in violent crimes like murder after Delhi. Considering crimes per 1 lakh population, Bangalore ranked seventh in the total crime rate. ${ }^{4}$

In Andhra Pradesh, the crime rate dipped by $6 \%$. Road accidents increased by $3 \%$ and fatalities by $6 \%$, while the number of murders reduced by $11 \%$. National Crime Records Bureau (NCRB) also reported that Andhra Pradesh had registered more than double the number of cases as compared to the other three states- Kerala, Tamil Nadu and Karnataka (“AP crime rate dips by $6 \%$ in 2019”, 2019). It was also found that Andhra Pradesh recorded the higher number of crimes against women among the South Indian states with 17,909 crimes with Telangana coming 2 nd with 17,521 crimes. $^{5}$ Kerala and Tamil Nadu have a significantly higher crime rate (NCRB, 2016). Delhi stood first with 1 , 451 victims in 1,317 road accidents, while Chennai (the capital of Tamil Nadu) was in second place with 1,404 victims in 1,312 road accidents. ${ }^{6}$ Hyderabad, the capital of Telangana recorded the highest number of drunk driving deaths among 53 urban areas. ${ }^{7}$

According to the National Poisons Information Centre, India reported the highest incident rate in the world, where about 50k dies every year. Factors responsible for these events were poverty, illiteracy, ignorance and product availability. A significant number of victims of poisoning were from the low economic status. ${ }^{8}$ A regional study from Tamil Nadu of suicide death reported that out of 38836 deaths, deaths relating to injuries accounted for $18.5 \%$ of total death and half of these were suicides. However, female suicide rates were109 out of 100000 while that of male was 98 and $49 \%$ deaths in women those are from socially and economic weaker sections. A community based study in Kerala revealed rural Tamil Nadu has highest suicide rate in the world and causes varied among individual and dependent on family and societal level factors. ${ }^{3}$ A community information based study also revealed that mortality rate and year of life lost was high, 54.9\% for unintended injuries death and $82.2 \%$ for suicides were reported. ${ }^{9}$

Hence, the potential determinants behind the different external causes in the South Indian states (Tamil Nadu, Karnataka, Kerala, Telangana and Andhra Pradesh) demands imminent analysis and introspection. This study used Bayesian Logistic Regression, combining all the plethora of external causes of deaths under one umbrella (NFHS data does not provide the breakup of external causes of death) to find the most significant factors affecting such deaths to counter them and help in effective policy making in successfully minimizing the fatalities in the long run.

\section{Materials and methods}

This study used the NFHS-4, 2015-16 data, a survey comprising all the 7 Union Territories and the 29 different States of India (640 districts in total), where data was collected regarding deaths due to external causes. 601,509 households were interviewed in this survey comprising 112,122 men aged 15-54 years and 699,686 women aged 15-49 years. $^{10}$

In NFHS-4, information was asked on whether any usual member of the sampled household died due to external causes since January 2012. For the deceased, information on age at death and sex was available on the household level. This information was collected from the head of the household. In this study, if the death occurred due to accidents, suicides, poisoning, homicide, or violence, then it was coded as (' 1 '), survived persons were coded as (' 0 ') and don't know cases as (' 8 '). The "don't know" cases were taken as "no" in this analysis.

The characteristics such as age and sex of the deceased and the household head, educational qualification of the family members, the drinking habit of the household members (any household member drinks alcohol-yes, if not-no), any household member having access to mass media (Newspaper, Radio, Television), the number of members in the family, the wealth index the households belong to (poor, middle, rich), place of residence, owning a four or two-wheeler vehicle were taken as independent variables.
Most of the individual characteristics of the deceased were not available in the collected data, so proxy variables from corresponding members of the households were considered based on available literature for analysis. In the case of educational qualification, the educational level of a person with the highest attainment was taken. It was assumed that the person with higher education might influence the behavior of all members including the deceased adult. Similarly, the mass media access of any adult member was taken as a proxy of the mass media access of the deceased. Further, alcohol consumption by any of the household members was taken as an independent variable. The data did not provide information for behavioral factors such as smoking and drinking of the deceased. The behaviors of household members were taken as either a proxy for the deceased's behavior. Here, five categories of wealth quantile variables were clubbed into three, 'poorest' and 'poorer' as poor, 'middle' as middle, and 'richer' and 'richest' as rich. Information on the household having two-wheelers (having motorcycle or scooter) or four-wheelers (having car or truck) was recorded using the binary response variable ("0" as "no" and " 1 " as "yes").

For the sake of analysis, the National data was split according to the south Indian states- Karnataka, Tamil Nadu, Kerala, Andhra Pradesh, and Telangana. Karnataka contained 60,733 samples with 116 fatalities due to external causes. Tamil Nadu contained 61,671 samples with 148 external deaths. Kerala contained 25,223 samples with 48 fatalities due to external causes. Andhra Pradesh contained 23,602 samples with 69 external deaths and Telangana contained 17,080 samples respectively with 53 fatalities due to external causes.

An optimal sample size is imperative to obtain the desired level of validity of statistical results. The sample size considered here, for five states, is quite low in comparison to the original population and considering the number of deaths due to external causes, conventional frequent statistical techniques could not be applied for proper analysis and interpretation because of the low sample size. The Bayesian methodology is equipped to handle data with such small sample sizes. The simulation-based on Markov Chain and Monte Carlo (MCMC) is used here to obtain the stationary distribution of the required distribution (posterior). The Monte Carlo estimates the properties of distribution by studying random samples from it while the Markov Chain property helps to generate random samples by a special sequential process, where each sample becomes the foundation or stepping stone for the next random sample. ${ }^{11}$ Hence, by using Bayesian with MCMC simulation, we approach this problem in this paper. The entire analysis has been done using Stata 16.0 software.

\subsection{Bayesian methodology}

Bayesian analysis is more accurate than an asymptotic approximation in the case of small area sample surveys. ${ }^{12}$ For arbitrarily rare events, a large sample size (or dataset) is imperative to arrive at the correct decision with good accuracy. The best result generally arrives when the data size grows quickly with rarity in an attempt to increase the expectation of the number of observations of the required rare event. This method is used to improve the final estimates, lessen the uncertainty associated with the situation, and efficiently managing rare events. ${ }^{13}$ Bayesian Framework provides probabilistic attention to uncertainty, which forms the basic foundation in predicting rare events, where generating new related samples is imperative for efficient analysis.

\subsection{The Bayesian approach of logistic regression}

The bayesian method uses an appropriate prior distribution. For regression models, the regression coefficients $\boldsymbol{\beta}$, $a$ normal prior distribution $\mathrm{N}_{\mathrm{p}}\left(\mu_{0}, \sum_{0}\right)$ (p-dimensional) is chosen where $\boldsymbol{\mu}_{0}$ is the prior mean vector and $\Sigma_{0}$ is the prior covariance matrix.

For $\mathrm{j}=1,2 \ldots \mathrm{p}, \beta_{\mathrm{j}} \sim \mathrm{N}\left(\mu_{\mathrm{j}}, \sigma_{\mathrm{j}}^{2}\right)$.

Now, from Bayes' theorem, the posterior distribution is: 


$$
\begin{aligned}
& \text { Posterior }=\prod_{i=1}^{n}\left[\left(\frac{e^{\beta_{0}+\beta_{1} \mathrm{X}_{i 1}+\ldots+\beta_{\rho} \mathrm{X}_{i p}}}{1+e^{\beta_{0}+\beta_{1} X_{i 1}+\ldots+\beta_{\rho} X_{i p}}}\right)^{y i}\left(1-\frac{e^{\beta_{0}+\beta_{1} \mathrm{X}_{i 1}+\ldots+\beta_{\rho} \mathrm{X}_{i p}}}{1+e^{\beta_{0}+\beta_{1} X_{i 1}+\ldots+\beta_{\rho} X_{i p}}}\right)^{\left(1-y_{i}\right)}\right] \\
& \quad \times \prod_{j=0}^{p} \frac{1}{\sqrt{2 \pi \sigma_{j}}} \exp \left\{-\frac{1}{2}\left(\frac{\beta_{\mathrm{j}}-\mu_{\mathrm{j}}}{\sigma_{\mathrm{j}}}\right)^{2}\right\}
\end{aligned}
$$

The first essential step involves the creation of a probability model for the available data. In this case, an appropriate probability model is a Bernoulli distribution model with a normal prior. Subsequently, the likelihood function is multiplied with the prior distribution to find the posterior distribution. Finally, using MCMC, samples are generated from the posterior distribution. The MCMC method converges over time into the stationary distribution.

\subsection{Graphical summaries or convergence diagnostics}

For the below 4 plot descriptions (time series, trace, density and auto-correlation) reference should be made in the Appendix section which has the required Figs. 1-5.

Time series plot: One of the tests for convergence diagnosis used in Bayesian analysis with MCMC. The time series plot indicated a good convergence because the three independent generated chains are overlapping, i.e., traversing the sample space in the same way.

Trace Plot: Here, the iteration number is plotted against the parameter value at each iteration. No long-term drifts or trends or drifts are visible, hence convergence can be concluded.

Density plot: For convergence, the kernel density plots must not be multi-modal and preferably bell-shaped (although not exactly). From Appendix, the convergence criteria look to be satisfied.

Autocorrelation plot: The autocorrelation should get smaller as the lag increases, indicating independent samples, which is evident in (Appendix), directing towards convergence.

Hence, from the above visual explorations or graphical summaries, we are satisfied with the MCMC convergence for the important factors. Next, we will be using Gelman-Rubin diagnostics for all model parameters to confirm convergence and analyze and interpret the results.

\subsection{Gelman-Rubin convergence diagnostic}

The termination of the Markov chain Monte Carlo (MCMC) simulation using Gelman-Rubin convergence diagnostic is a popular approach and is imperative for Bayesian analysis. In this method, the within-chain and between-chain variance for each model parameter is computed, finally providing a numerical convergence summary for all model parameters as well as for the full model. The necessary requirement for the convergence diagnostic is: the value of the statistic has to be less than 1.1 for the full model as well as the model parameters.

\section{Results}

The prevalence (per lakh population) and percentage of external deaths to total deaths among adults in the southern states of India by socio-economic and demographic characteristics were shown in Table 1. For all the states, the percentage of external causes of deaths decreased with increasing age. But the result is not uniform in case of prevalence. The highest prevalence was 263 per lakh population, observed in the age group 30-34 years for Karnataka. For Tamil Nadu, it was 395 per lakh population at 25-29. Kerala, Andhra Pradesh and Telangana accounted for 331,489 and 723 deaths due to external causes per lakh population for the 55-59 years (age-group).

The percentage and the prevalence of external deaths were higher among males irrespective of all the states. For males, Karnataka, Tamil Nadu, Kerala, Andhra Pradesh and Telangana showed respectively 326, $365,310,468$ and 513 external deaths among adults per lakh population. The study found that the prevalence of the external cause of deaths was highest in female-headed households in all the states. In case of place of residence, Karnataka (223 deaths per lakh population), Andhra Pradesh (307 deaths per lakh population) and Telangana showed a high prevalence of external causes of deaths in rural areas. In case of Tamil $\mathrm{Nadu}$, the prevalence was the same for both rural and urban areas (238 deaths per lakh population) and the prevalence was highest among urban residents (229 deaths per lakh population) in case of Kerala.

According to the study, the prevalence of external causes of deaths decreased with an increase in wealth index and the result was uniform except Kerala where the people belonging to the middle wealth quintile had the highest prevalence of 354 deaths per lakh population than the other groups. The study showed that with an increase in educational qualification, the prevalence of external causes of deaths was decreasing and the result was uniform irrespective of all states.

The results of the Bayesian logistic regression analysis to find the socio-economic and demographic factors affecting the external causes of deaths among adults in South Indian states were presented in Table 2. The table showed the odds ratio as well as the convergence diagnostics (Gelman-Rubin, denoted by Rc) of the model parameters for all the South Indian states. The convergence of the important factors has been illustrated by Figs. 1-5 in the Appendix section.

In case of Karnataka, the model converged for sex of the deceased, sex of household head and the number of members in the family. The study found that females and adults belonging to female-headed households were 0.85 times less likely and 3.66 times more likely to die due to external causes than the counterparts. The model also found that the odds of external deaths decreased (Odds ratio 0.87) with the increase in the number of family members.

In case of Tamil Nadu, the model converged for sex of the deceased, the place of residence, owning a two or four-wheeler car and access to mass media. The study found that females and rural residents were respectively 0.67 and 0.04 times less likely to die due to external causes. Owning a two or four-wheeler significantly lowered the risk of external causes of deaths. The model also showed that the odds of external causes of deaths were significantly lower among people who had mass media access.

In case of Kerala, the significant factors were the sex of the deceased, the place of residence, owning a vehicle and the drinking habit of household members. The study found that females and rural residents were respectively 0.74 and 0.30 times less likely to die due to external causes. Owning a two or four-wheeler lowered the risk of deaths due to external causes. The model also found that the odds of external causes of deaths were significantly high among people who had drinking habits.

In case of Andhra Pradesh, the model converged for sex of deceased, the number of family members and the place of residence. The study found that females and rural residents were significantly 0.74 times less likely and 1.41 times more likely to die due to external causes. The model also found that the odds of external causes of deaths was decreasing (Odds ratio 0.75 ) with the increase in the number of family members.

In the case of Telangana, the model converged for sex of the deceased, sex of household head, the place of residence and the wealth index. The study found that females were 0.86 times less likely to die due to external causes. Adults belonging to female-headed households and rural areas were having more risks ( 3.41 times and 1.40 respectively) of fatalities owing to external causes. The model also showed that the odds of deaths for the middle and rich class was 0.02 and 0.76 times less as compared to the poor class respectively.

\section{Discussion}

For all the states, the percentage of external causes of deaths decreased with increasing age but the risk increased with increment of age. A study found that with age the risk of dying for external causes was increasing but the relationship between age and risk of deaths due to external causes was not linear. ${ }^{38}$ The study showed that with the 
Table 1

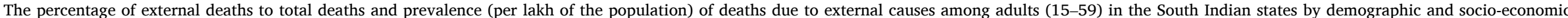
characteristics.

\begin{tabular}{|c|c|c|c|c|c|c|c|c|c|c|}
\hline \multirow[t]{2}{*}{ Covariates } & \multicolumn{2}{|l|}{ Karnataka } & \multicolumn{2}{|l|}{ Tamil Nadu } & \multicolumn{2}{|l|}{ Kerala } & \multicolumn{2}{|l|}{ Andhra Pradesh } & \multicolumn{2}{|l|}{ Telangana } \\
\hline & $\begin{array}{l}\text { Percentage of external } \\
\text { deaths to total deaths }\end{array}$ & $\begin{array}{l}\text { Prevalence } \\
\text { (per lakh) }\end{array}$ & $\begin{array}{l}\text { Percentage of external } \\
\text { deaths to total deaths }\end{array}$ & $\begin{array}{l}\text { Prevalence } \\
\text { (per lakh) }\end{array}$ & $\begin{array}{l}\text { Percentage of external } \\
\text { deaths to total deaths }\end{array}$ & $\begin{array}{l}\text { Prevalence } \\
\text { (per lakh) }\end{array}$ & $\begin{array}{l}\text { Percentage of external } \\
\text { deaths to total deaths }\end{array}$ & $\begin{array}{l}\text { Prevalence } \\
\text { (per lakh) }\end{array}$ & $\begin{array}{l}\text { Percentage of external } \\
\text { deaths to total deaths }\end{array}$ & $\begin{array}{l}\text { Prevalence } \\
\text { (per lakh) }\end{array}$ \\
\hline \multicolumn{11}{|l|}{ Age group } \\
\hline 15-19 & 64.3 & 175 & 61.9 & 160 & 66.7 & 125 & 52.9 & 290 & 37.5 & 126 \\
\hline $20-24$ & 46.0 & 148 & 54.55 & 225 & 90.0 & 306 & 40.0 & 170 & 56.3 & 326 \\
\hline $25-29$ & 46.8 & 231 & 61.1 & 395 & 25.0 & 34 & 26.7 & 286 & 43.8 & 251 \\
\hline $30-34$ & 48.1 & 263 & 37.1 & 169 & 50.0 & 116 & 35.3 & 214 & 35.0 & 339 \\
\hline $35-39$ & 15.0 & 151 & 20 & 115 & 28.6 & 130 & 29.0 & 298 & 24.0 & 286 \\
\hline $40-44$ & 19.8 & 183 & 33.3 & 292 & 26.3 & 177 & 25.7 & 360 & 14.8 & 244 \\
\hline $45-49$ & 9.7 & 199 & 13 & 189 & 28.0 & 226 & 22.7 & 362 & 17.1 & 337 \\
\hline $50-54$ & 6.5 & 164 & 14.0 & 372 & 19.5 & 317 & 14.3 & 408 & 14.3 & 506 \\
\hline 55-59 & 5.1 & 178 & 8.0 & 332 & 16.7 & 331 & 13.0 & 489 & 14.6 & 723 \\
\hline \multicolumn{11}{|l|}{ Sex } \\
\hline Male & 24.9 & 326 & 29.7 & 365 & 29.6 & 310 & 29.0 & 468 & 27.4 & 513 \\
\hline Female & 9.8 & 58 & 21.5 & 123 & 26.2 & 82 & 16.5 & 122 & 15.2 & 113 \\
\hline \multicolumn{11}{|c|}{ Sex of Household head } \\
\hline Male & 22.8 & 146 & 28.2 & 175 & 31.3 & 121 & 24.6 & 193 & 21.4 & 184 \\
\hline Female & 17.2 & 444 & 25.6 & 686 & 26.4 & 494 & 25.5 & 1072 & 27.2 & 1236 \\
\hline \multicolumn{11}{|c|}{ Place of Residence } \\
\hline Urban & 12.7 & 125 & 30.0 & 238 & 33.9 & 229 & 27.1 & 252 & 13.6 & 171 \\
\hline Rural & 27.6 & 223 & 24.6 & 238 & 25.5 & 165 & 24.2 & 307 & 29.6 & 388 \\
\hline \multicolumn{11}{|l|}{ Wealth index } \\
\hline Poor & 27.3 & 295 & 27.0 & 350 & 11.1 & 136 & 21.1 & 348 & 28.6 & 511 \\
\hline Middle & 22.8 & 178 & 19.9 & 210 & 32.5 & 354 & 27.8 & 348 & 28.8 & 466 \\
\hline Rich & 13.8 & 125 & 31.3 & 214 & 28.8 & 162 & 24.8 & 230 & 12.1 & 100 \\
\hline \multicolumn{11}{|c|}{ Number of members in the family } \\
\hline 4 members & 18.8 & 269 & 27.6 & 278 & 32.5 & 276 & 24.6 & 362 & 24.8 & 409 \\
\hline $\begin{array}{l}\text { More than } 4 \\
\text { members }\end{array}$ & 22.6 & 139 & 26.2 & 189 & 20.0 & 86 & 25.5 & 218 & 22.0 & 207 \\
\hline \multicolumn{11}{|c|}{ Educational qualification } \\
\hline Illiterate & 32.7 & 548 & 11.8 & 278 & 0.0 & 0 & 25.6 & 596 & 28.2 & 791 \\
\hline Primary & 17.6 & 425 & 30.8 & 403 & 25.0 & 575 & 19.4 & 363 & 22.2 & 396 \\
\hline Secondary & 20.2 & 181 & 25.9 & 266 & 26.2 & 217 & 27.1 & 314 & 27.4 & 362 \\
\hline Higher & 17.2 & 116 & 30.2 & 187 & 33.9 & 155 & 22.2 & 174 & 12.2 & 100 \\
\hline Total & 20.4 & 190 & 27.1 & 238 & 28.7 & 189 & 24.9 & 290 & 23.8 & 307 \\
\hline
\end{tabular}


Table 2

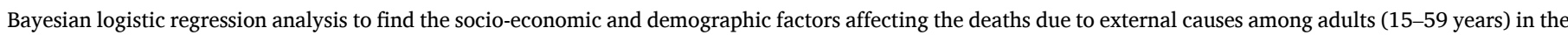
South Indian states.

\begin{tabular}{|c|c|c|c|c|c|c|c|c|c|c|}
\hline \multirow[t]{2}{*}{ Covariates } & \multicolumn{2}{|c|}{ Karnataka } & \multicolumn{2}{|c|}{ Tamil Nadu } & \multicolumn{2}{|l|}{ Kerala } & \multicolumn{2}{|c|}{ Andhra Pradesh } & \multicolumn{2}{|c|}{ Telangana } \\
\hline & $\begin{array}{l}\text { Odds } \\
\text { Ratio }\end{array}$ & $\begin{array}{l}\text { Convergence } \\
\text { diagnostics }\end{array}$ & $\begin{array}{l}\text { Odds } \\
\text { Ratio }\end{array}$ & $\begin{array}{l}\text { Convergence } \\
\text { diagnostics }\end{array}$ & $\begin{array}{l}\text { Odds } \\
\text { Ratio }\end{array}$ & $\begin{array}{l}\text { Convergence } \\
\text { diagnostics }\end{array}$ & $\begin{array}{l}\text { Odds } \\
\text { Ratio }\end{array}$ & $\begin{array}{l}\text { Convergence } \\
\text { diagnostics }\end{array}$ & $\begin{array}{l}\text { Odds } \\
\text { Ratio }\end{array}$ & $\begin{array}{l}\text { Convergence } \\
\text { diagnostics }\end{array}$ \\
\hline Age & 1.00 & $1.02(\mathrm{Rc}<1.1)$ & 1.00 & $1.01(\mathrm{Rc}<1.1)$ & 1.02 & $1.00(\mathrm{Rc}<1.1)$ & 1.01 & $1.00(\mathrm{Rc}<1.1)$ & 1.03 & $1.00(\mathrm{Rc}<1.1)$ \\
\hline \multicolumn{11}{|l|}{ Sex } \\
\hline Male ${ }^{\circledR}$ & & & & & & & & & 1 & \\
\hline Female & 0.15 & $1.02(\mathrm{Rc}<1.1)$ & 0.36 & $1.01(\mathrm{Rc}<1.1)$ & 0.26 & $1.01(\mathrm{Rc}<1.1)$ & 0.26 & $1.01(\mathrm{Rc}<1.1)$ & 0.14 & $1.00(\mathrm{Rc}<1.1)$ \\
\hline $\begin{array}{l}\text { Sex of Household } \\
\quad \text { head }\end{array}$ & & & N.C & & N.C & & N.C & & & \\
\hline Male ${ }^{\circledR}$ & & & & & & & & & 1 & \\
\hline Female & 3.66 & $1.00(\mathrm{Rc}<1.1)$ & & & & & & & 3.41 & $1.00(\mathrm{Rc}<1.1)$ \\
\hline $\begin{array}{l}\text { Age of household } \\
\text { head }\end{array}$ & N.C & & N.C & & N.C & & N.C & & N.C & \\
\hline $\begin{array}{l}\text { Number of members } \\
\text { in the family }\end{array}$ & 0.87 & $1.00(\mathrm{Rc}<1.1)$ & N.C & & & & 0.75 & $1.01(\mathrm{Rc}<1.1)$ & N.C & \\
\hline $\begin{array}{l}\text { Place of Residence } \\
\text { Urban }{ }^{\circledR}\end{array}$ & N.C & & & & & & & & & \\
\hline Rural & & & 0.96 & $1.01(\mathrm{Rc}<1.1)$ & 0.70 & $1.01(\mathrm{Rc}<1.1)$ & 1.41 & $1.05(\mathrm{Rc}<1.1)$ & 1.30 & $1.00(\mathrm{Rc}<1.1)$ \\
\hline $\begin{array}{c}\text { Education of } \\
\text { household } \\
\text { members }\end{array}$ & N.C & & N.C & & N.C & & N.C & & N.C & \\
\hline \multicolumn{11}{|l|}{ Illiterate ${ }^{\circledR}$} \\
\hline \multicolumn{11}{|l|}{ Primary } \\
\hline \multicolumn{11}{|l|}{ Secondary } \\
\hline \multicolumn{11}{|l|}{ Higher } \\
\hline \multicolumn{11}{|l|}{$\operatorname{Poor}{ }^{\circledR}$} \\
\hline Middle & & & & & & & & & 0.98 & $1.00(\mathrm{Rc}<1.1)$ \\
\hline Rich & & & & & & & & & 0.24 & $1.00(<1.1)$ \\
\hline $\begin{array}{l}\text { Drinking habit of } \\
\quad \text { household } \\
\text { members }\end{array}$ & N.C & & N.C & & & & N.C & & N.C & \\
\hline \multicolumn{11}{|l|}{$\mathrm{No}{ }^{\circledR}$} \\
\hline Drinks & & & & & 1.01 & $1.00(\mathrm{Rc}<1.1)$ & & & & \\
\hline $\begin{array}{l}\text { Mass Media access } \\
\text { to household } \\
\text { members }\end{array}$ & N.C & & & & N.C & & N.C & & N.C & \\
\hline No access ${ }^{\circledR}$ & & & & & & & & & & \\
\hline $\begin{array}{l}\text { At least one media } \\
\text { access }\end{array}$ & & & 0.58 & $1.02(\mathrm{Rc}<1.1)$ & & & & & & \\
\hline $\begin{array}{l}\text { Access to Car } \\
\text { No }{ }^{\circledR}\end{array}$ & N.C & & & & & & N.C & & N.C & \\
\hline Yes & & & 0.68 & $1.00(\mathrm{Rc}<1.1)$ & 0.39 & $1.00(\mathrm{Rc}<1.1)$ & & & & \\
\hline
\end{tabular}

N.C signifies non-convergence.

Rc signifies Gelman-Rubin convergence diagnostic.

$\mathrm{Rc}<1.1$ signifies convergence.

increase of educational qualification, the prevalence of external causes of deaths was decreasing and the result was uniform irrespective of all south Indian states. Studies show that households having educated members are less likely to die from external causes than households with illiterate members. Therefore, education is considered as one of the three basic indicators for measuring the socioeconomic status of an individual. $^{2,39,40}$ Educated people are generally more informed and conscious about how to avoid external injuries (like obeying traffic rules, etc.), hence the risk is less for them.

The risk, as well as the prevalence of fatalities owing to external causes, was higher among males than females for all 5 states. A higher number of suicides, unintentional injuries, and homicide rates are observed in almost every age group for men in developed and developing countries. ${ }^{14-17}$ Some of the circumstances or situational factors result in extended exposure of external deaths among men as a strong positive association exists between gender, risk-taking ability, and injury. ${ }^{18-20}$

The prevalence of the external cause of deaths was highest in femaleheaded households in all five states. External causes of deaths are sometimes associated with family disputes and family position. ${ }^{21}$ The majority of Indian families are male-headed and generally become female-headed after the death of the male head. This change of household head may mentally affect the young members of the family. In the Indian scenario, female headship and poverty were significantly positively associated and they often carry a higher dependency burden. ${ }^{22}$ The principal bread-earners of female-headed families are mostly women, who have lower average earnings than men. It was reported that Indian women earn $19 \%$ less than men. Since catering to individual demands of family members and taking proper care of herself are often not feasible, they might feel neglected and dejected which sometimes leads to suicidal tendencies among them. ${ }^{23}$ Mental, emotional and economic stress are the ramifications resulting from the overburdened responsibilities they have to carry. From a societal perspective, female-headed households are not much respected or looked upon by society as compared to the male-headed households in India, and also they are more vulnerable to poverty. ${ }^{24}$ This is also one of the imperative reasons that they also developmental stress and fatigue to get accustomed to the system. Often children and youth belonging to female-headed households are forced to pursue career opportunities that reduce the financial burden on the family. The objective comes down to how fast they can be bread earners for the family. This type of pressure and stress can remain for the entire life of a child born and nurtured in such families. The compounding of all these factors, together can initiate suicidal tendencies in the minds of young children of such families. But 
in the case of risk of deaths due to external causes, the model converged for Karnataka and Telangana for this factor.

The prevalence of external causes of deaths is more in rural areas in Karnataka, Andhra Pradesh, and Telangana. The adult deaths are more prominent for Tamil Nadu state those who are living in both rural and urban areas. Kerala and Tamil Nadu show insignificance in adult deaths regardless of residence. The prevalence of external causes of deaths decreased with an increase of wealth index (except Kerala) but the relationship is not significant. Similarly, results were found significant in another study also. ${ }^{38}$ An wealthy individual is less exposed to extremely hazardous and laborious work for their livelihood as a result, the chances of external accidents are significantly low. However, financial security is mostly with the rich section, they are less prevalent for financial stress and also death from different external causes as compared to the lower wealth quintiles individuals.

The study found a strong significant association with the number of family members. The prevalence of external deaths was found less in large families. Living with family members usually promotes compliance with the family norms, improves health practices, and family guidance can help in reducing stress since guidance or a much needed backing in difficult situations is available. Family members usually do exercise some amount of control in terms of limiting habits like smoking, drug abuse, drinking and encouraging to maintain regular exercise and taking sufficient rest. ${ }^{2,25,38}$ But in case of risk of dying by external causes, the model converged for Karnataka and Andhra Pradesh The two states have resulted in decreasing the risk of dying due to unnatural causes with the increase in the number of family members.

The risk of deaths attributable to external causes was found to be significantly high among rural residents of Tamil Nadu and Kerala and low among rural residents of Andhra Pradesh and Telangana.

The risk of external causes of deaths was found to be significantly less among residents of Tamil Nadu who had access to at least one source of mass media. This can be explained by the fact that mass media can go a long way in positively spreading awareness about road safety for avoiding accidents, motivational videos for treating depression and suicidal thoughts, and a lot of affirmative advice in dealing with tough situations. Although, a study reported that mass media is not doing enough to create awareness about suicides in Tamil Nadu. ${ }^{26}$

The risk of external causes of deaths was found to be significantly less among people who owned a two or four-wheeler car and this result was true for the states of Tamil Nadu and Kerala. The risk of external causes of deaths was significantly decreasing with increasing wealth index for residents of Telangana. Generally, in most Indian societies, access to a car is the implication of the wealthier class. Being part of the wealthy strata, people, in general, become more aware, informed, and conscious about external deaths like accidents, suicides, etc. Moreover, the wealthier class has fewer financial problems and generally a lot of influence in almost every aspect of life (for example: landing a job using contacts and influence, having enough backing in terms of money and contacts to open a business, etc.), and this works for them in the way of avoiding the external deaths as compared to the middle of the lower wealth quantile.

In the case of Kerala, people who had drinking habits were more prone to death due to external causes. In Kerala. Alcoholism is becoming a serious problem among adults. It is developing as a major public health problem as well as a social menace. The state of Kerala is characterized as "God's own Country". But nowadays it is going towards the path of attaining the name "the Alcohol's Own Country" as the frequency and quantity of alcohol consumption have a cumulative effect on external causes of mortality among adults irrespective of gender. ${ }^{27-30}$

\subsection{Limitations of the study}

In the NFHS-4 survey, a direct question was asked about external causes of deaths to the households. Since there is a lot of social stigmas associated with such information especially in the case when a family member died of suicide or poisoning or related causes, the household head is reluctant to supply accurate information, resulting in underreporting or misreporting. Deaths of the feminine gender generally remain underreported since times immemorial. As the National Family Health Survey data give limited sample and in some cases existence of class-biasness causes sometimes non-uniform results that are (the model become non-convergent) affecting the potential determinants of deaths due to external causes in different states (including the South Indian States). Also, since the classification of external deaths (for example, suicide, murder, accident, homicide, etc.) are not provided in the data, we had to consider all the external causes together. Had the exact classification of external causes of deaths been available, pinpoint focus and analysis could have been carried out to better understand the exact factors affecting these deaths. Accordingly, efficient measures could have been applied to reduce the number of deaths.

\section{Conclusion}

The present study has documented the prevalence as well as the important factors behind the external causes of adult deaths in South Indian states of India. The study found that the potential determinants of external causes of adult deaths are not uniform in all states except sex. Overall the significant potential factors such as the place of residence, sex of household heads, the number of family members, drinking habit, owning a car, and mass media access.

To reduce premature death in the South Indian states, people must adopt a joint family norm, abide by a healthier lifestyle rather than excessive alcohol consumption. The socio-economic status, wealth of the households have a significant relationship with adult deaths. Furthermore, mass media also plays an effective role in providing, spreading awareness and motivation for reducing stress, treating depression and suicidal thoughts, and numerous affirmative advice in dealing with tough situations.

Mental health problem was analyzed as the leading cause for suicide and the government's failure to address and work upon the issues exacerbated the increase in the number of suicides. ${ }^{31}$ Despite the development, high literacy rate, and comparatively less unemployment rates the south Indian states face a high prevalence and risk of external deaths due to rampant interpersonal stress, relationship complications, financial problems, alcohol consumption, and gender-related issues. Educated youths have high aspirations which clash with the highly rigid social norms, resulting in the development of stress among them. The inability to deal with growing levels of stress in personal and professional lives could be the reasons why many youngsters are triggered to take the extreme step in southern states. ${ }^{32}$

It has also been found that death from unnatural deaths among the young age group was due to parental psychiatric disorder. ${ }^{33}$ This factor is widely recognized for developing different programs to minimize the event of suicide and homicide in psychiatric populations. In that case, effective treatment strategies are needed for affected families.

Elimination of deaths due to external causes is not possible, but it can be minimized. According to Smith et al. (2009) ${ }^{33}$ to effectively optimize premature mortality due to external causes, contemporary national efforts need to be strengthened and supplemented with effective and innovative actions. There is a need for regular monitoring of deaths due to non-medical reasons in these states for better guidance of the national and state policies related to health and health behavior including their mental health. ${ }^{34-37}$

\section{Funding and acknowledgements}

This research received no specific grant from any funding agency, commercial entity or not-for-profit organization. 


\section{Declaration of competing interest}

No conflict of interest was reported by all authors.

\section{Appendix}

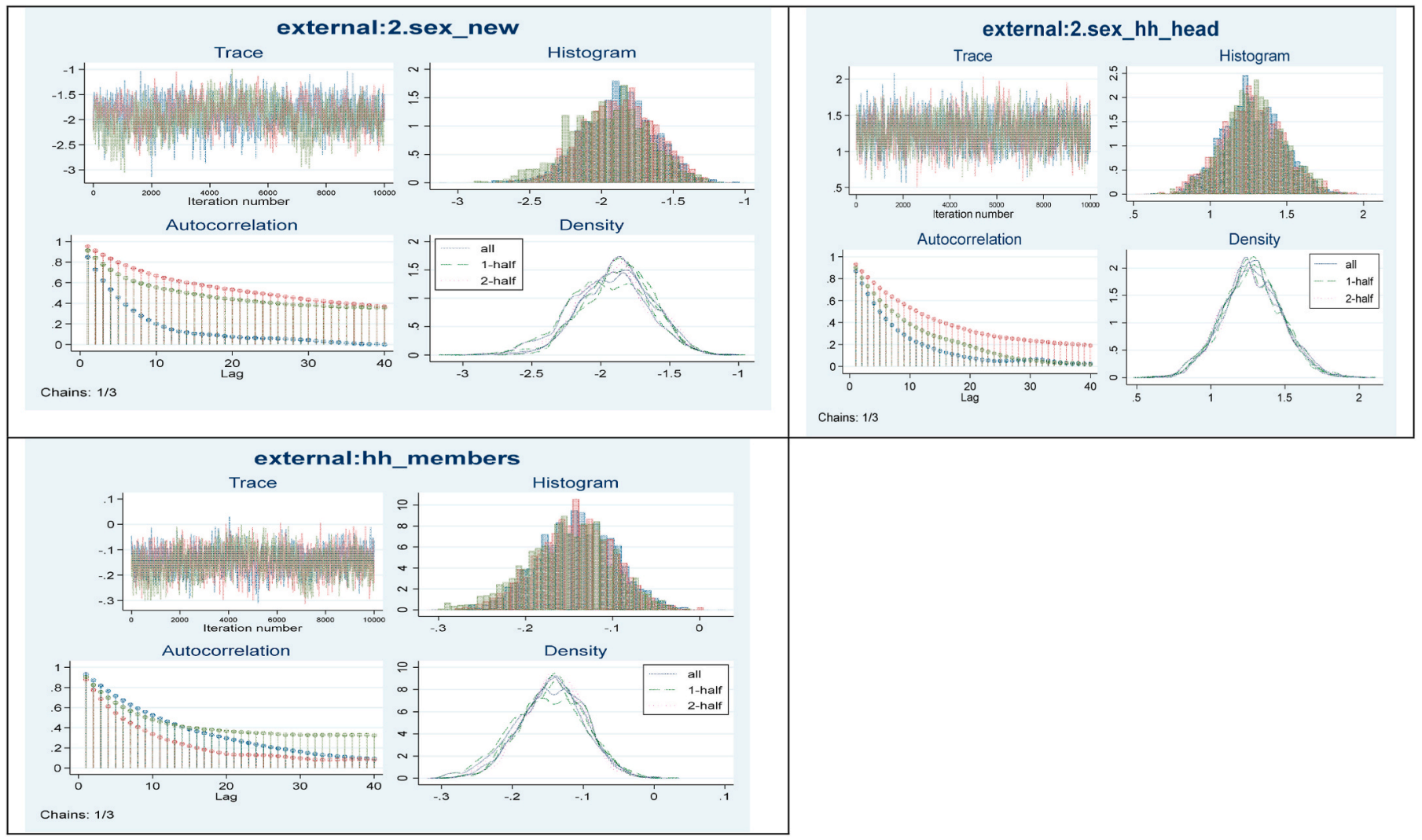

Fig. 1. Mcmc convergence diagnostic for Karnataka. 


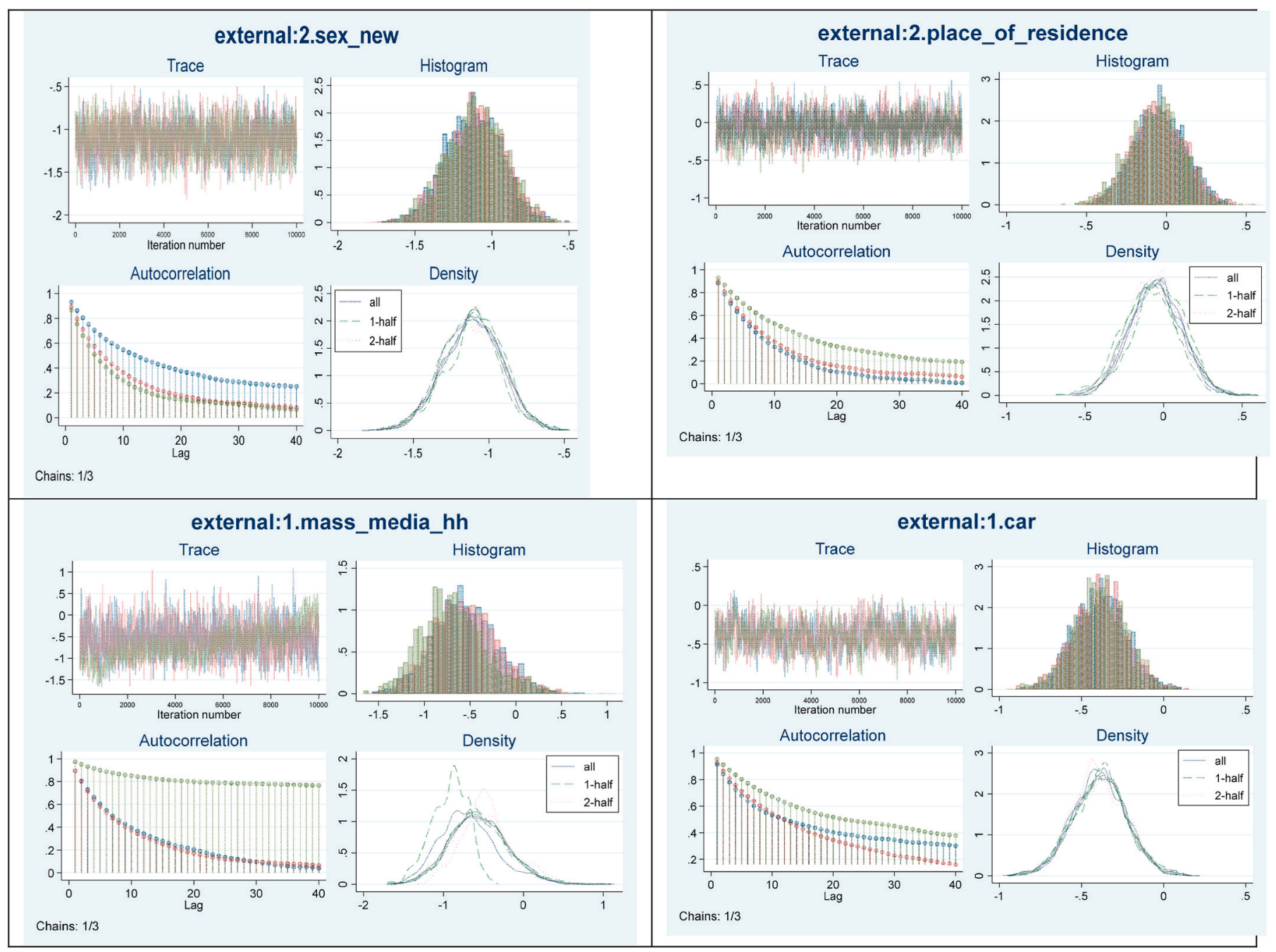

Fig. 2. Mcmc convergence diagnostic for Tamil Nadu. 


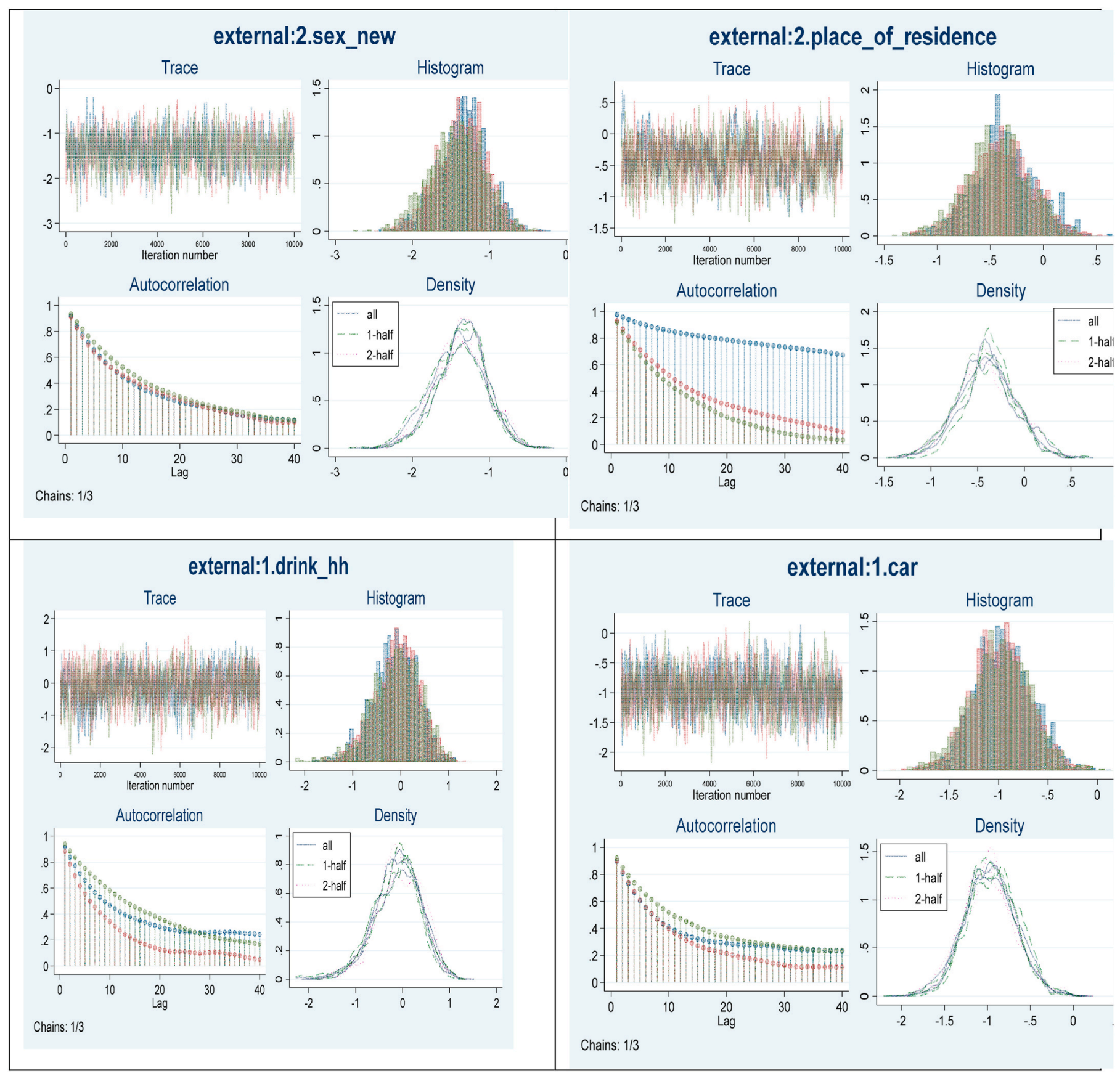

Fig. 3. Mcmc convergence diagnostic for Kerala. 

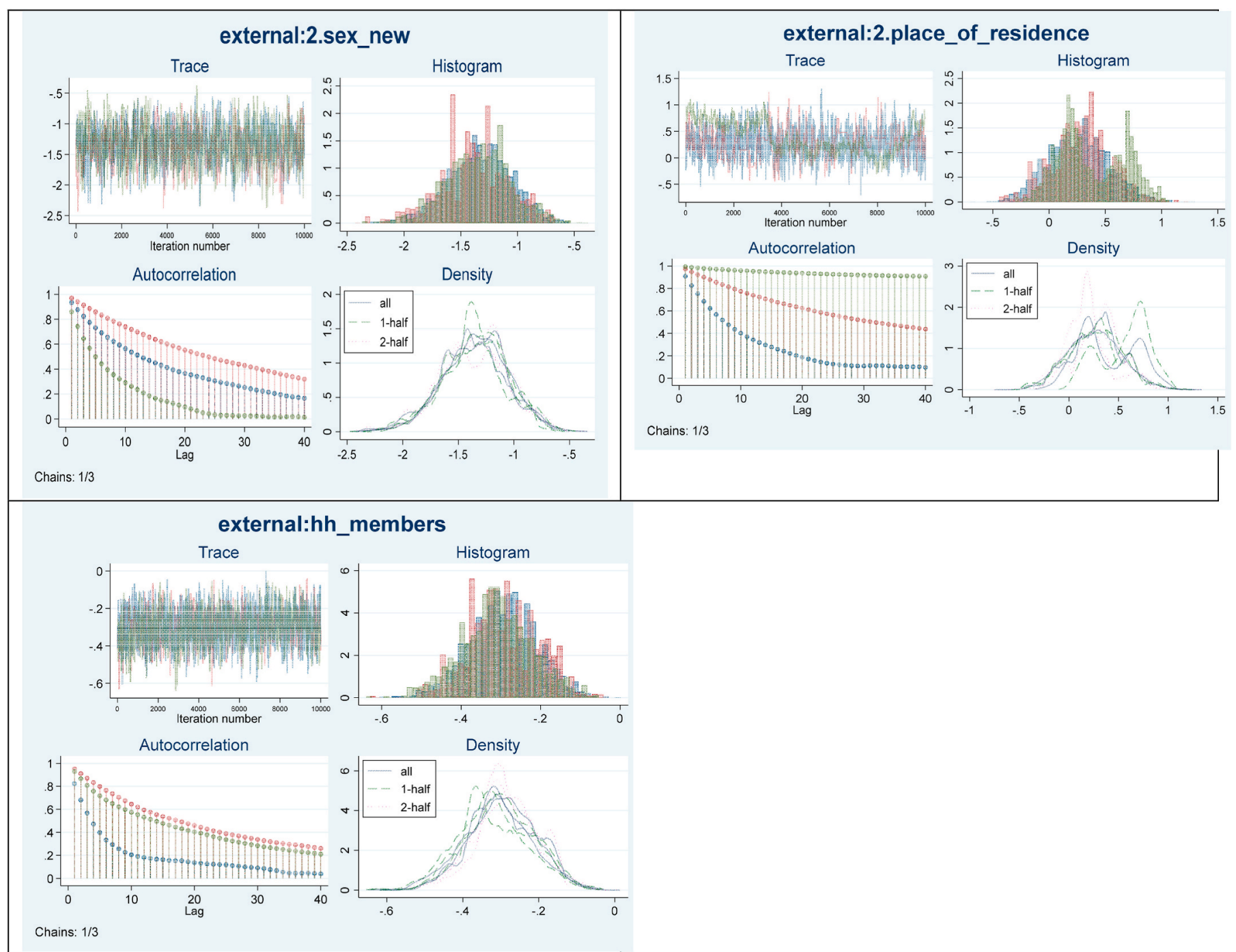

Fig. 4. Mcmc convergence diagnostic for Andhra Pradesh. 

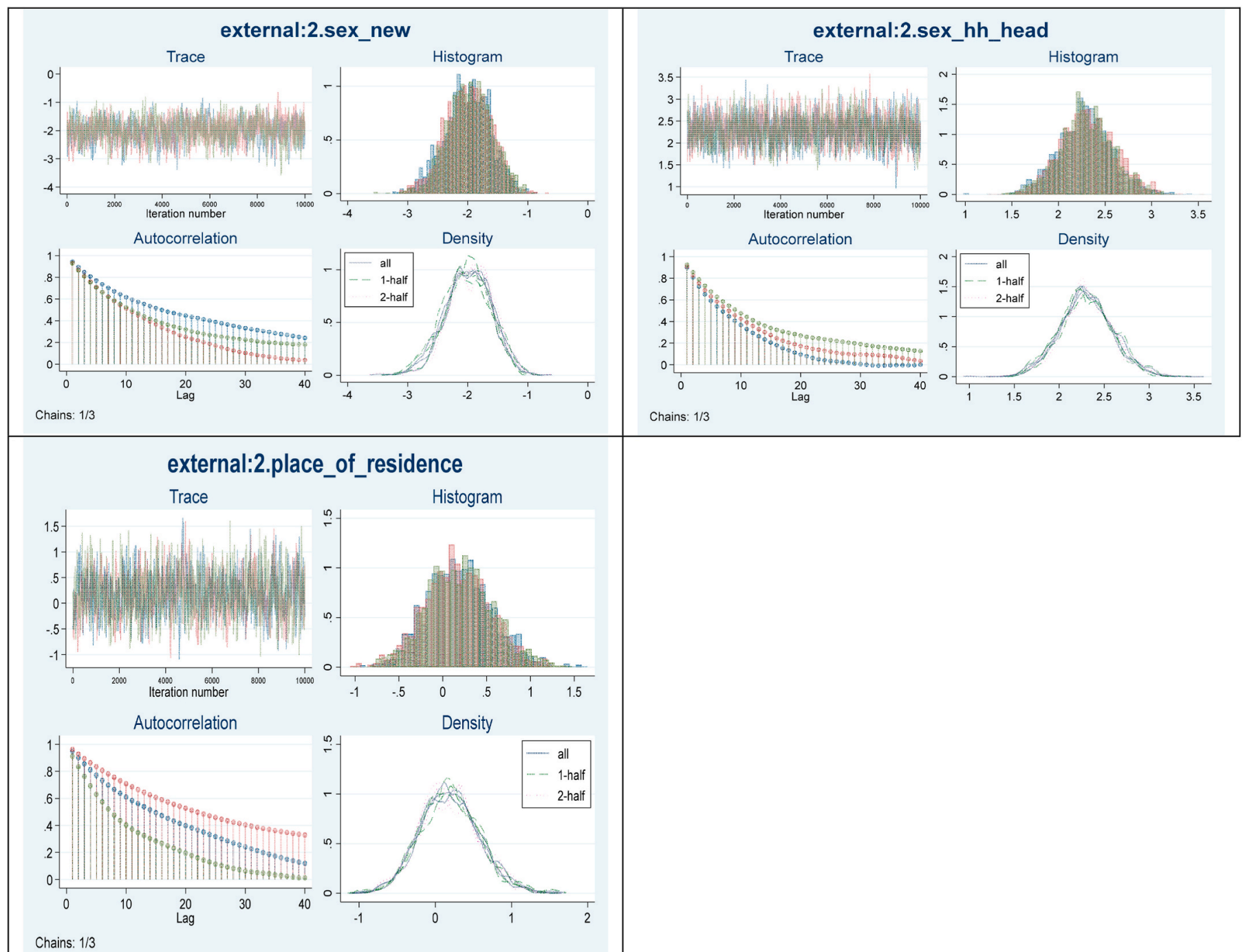

Fig. 5. MCMC Convergence Diagnostic for Telangana. Here, ssex_new signifies the variable sex for both survived as well as deceased. sex_hh_head signifies the sex of household head. hh_members signifies the number of members in the household.

place_of _residence signifies the place of residence of survived as well as deceased. drink_hh signifies the drinking habit of household members. car signifies owning two or four wheeler by the household.

\section{References}

1 Saikia N, Bhat PM. Factors affecting adult mortality in India: an analysis of national family health surveys of 1992-93 and 1998-99 (NFHS I and II). Demogr India. 2008;37 (2):291-302.

2 Saikia N, Ram F. Determinants of adult mortality in India. Asian Popul Stud. 2010;6 (2):153-171.

3 Soman CR, Safraj S, Kutty VR, Vijayakumar K, Ajayan K. Suicide in South India: a community-based study in Kerala. Indian J Psychiatr. 2009;51(4):261.

4 Mohammad A, K M PK. Karnataka Second Safest State in South India, Says NCRB Data. The New Indian Express; 2017. Retrieved from https://www.newindianexpress. com/states/karnataka/2017/dec/01/karnataka-second-safest-state-in-south-india-sa ys-ncrb-data-1715450.html.

5 Babu N. Andhra Pradesh Tops List in Crimes against Women in South in South India. The Times of India; 2019 (Retrieved from).

6 Narayanan V. Chennai City Has a Poor Record on Road Safety. The Hindu; 2019. Retrieved from https://www.thehindu.com/news/cities/chennai/city-has-a-poor-rec ord-on-road.

7 Nanisetti S. Hyderabad Tops in Drunk Driving Deaths. The Hindu; 2019. Retrieved from https://www.thehindu.com/news/cities/Hyderabad/city-tops-in-drunk-drivingd eaths/article29956545.ecesafety/article29772170.ece\#: :text=While\%20Delhi\% 20stood\%20first $\% 20$ with,victims\%20in\%201\%2C312\%20road\%20accidents.
8 Asawari R, Atmaram P, Bhagwan K, Priti D, Kavya S, Jabeen GA. Toxicological pattern of poisoning in urban hospitals of western India. J Young Pharm. 2017;9(3): 315

9 Bose A, Konradsen F, John J, Suganthy P, Muliyil J, Abraham S. Mortality rate and years of life lost from unintentional injury and suicide in South India. Trop Med Int Health. 2006:11(10):1553-1556.

10 International Institute for Population Sciences, ICF. National Family Health Survey, India 2015-16. Mumbai: International Institute for Population Sciences (IIPS) and ICF; 2017.

11 Van Ravenzwaaij D, Cassey P, Brown SD. A simple introduction to Markov chain Monte-Carlo sampling. Psychonomic Bull Rev. 2018;25(1):143-154.

12 Albert JH, Chib S. Bayesian analysis of binary and polychotomous response data. J Am Stat Assoc. 1993;88(422):669-679.

13 Fudenberg D, He K, Imhof LA. Bayesian posteriors for arbitrarily rare events. Proc Natl Acad Sci Unit States Am. 2017;114(19):4925-4929.

14 Dannenberg AL, Baker SP, Li G. Intentional and unintentional injuries in women an overview. Ann Epidemiol. 1994;4(2):133-139.

15 Schnitzer PG, Runyan CW. Injuries to women in the United States: an overview. Women Health. 1995;23(1):9-27.

16 Moniruzzaman S, Andersson R. Cross-national injury mortality differentials by income level: the possible role of age and ageing. Publ Health. 2008;122(11): 1167-1176.

17 Sorenson SB. Gender disparities in injury mortality: consistent, persistent, and larger than you'd think. Am J Publ Health. 2011;101(S1):S353-S358. 
18 Wilsnack RW, Vogeltanz ND, Wilsnack SC, Harris TR. Gender differences in alcohol consumption and adverse drinking consequences: cross-cultural patterns. Addiction. 2000;95(2):251-265.

19 Turner C, McClure R, Pirozzo S. Injury and risk-taking behavior-a systematic review. Accid Anal Prev. 2004:36(1):93-101.

20 Granié MA. Effects of gender, sex-stereotype conformity, age and internalization on risk-taking among adolescent pedestrians. Saf Sci. 2009;47(9):1277-1283.

21 Kitulwatte IDG, Edirisinghe PAS, Pratheepa Mendis HKNL, Wijesinghe PR, Fernando A, Abeyrathne ARM. Study on the Pattern of Unnatural Deaths of Women Brought for Medico-Legal Autopsy. 2017.

22 Buvinić M, Gupta GR. Female-headed households and female-maintained families: are they worth targeting to reduce poverty in developing countries? Econ Dev Cult Change. 1997;45(2):259-280.

23 Bhattacharyya R. March 7). Gender Pay Gap High in India: Men Get Paid Rs 242 Every Hour, Women Earn Rs 46 Less. The Economic Times; 2019. Retrieved from https://e onomictimes.indiatimes.com/magazines/panache/gender-pay-gap-still-high-wom en-in-india-earn-19-pc-less-than-men-report/articleshow/68302223.cms?utm_sourc $\mathrm{e}=$ contentofinterest\&utm_medium_ext\&utm_campaign $=$ cppst.

24 Gangopadhyay S, Wadhwa W. Are Indian Female-Headed Households More Vulnerable to Poverty. New Delhi: Bazaar Chintan; 2004:1-2.

25 Antonucci TC. Social supports and social relationships. In: Binstock RH, George LK, eds. Handbook of Aging and the Social Sciences. 1990.

26 Armstrong G, Vijayakumar L, Niederkrotenthaler T, et al. Assessing the quality of media reporting of suicide news in India against World Health Organization guidelines: a content analysis study of nine major newspapers in Tamil Nadu. Aust $N$ Z J Psychiatr. 2018;52(9):856-863.

27 Thun MJ, Peto R, Lopez AD, et al. Alcohol consumption and mortality among middleaged and elderly US adults. N Engl J Med. 1997;337(24):1705-1714.

28 Dawson DA. Alcohol and mortality from external causes. J Stud Alcohol. 2001;62(6): 790-797.
29 Das SK, Balakrishnan V, Vasudevan DM. Alcohol: its health and social impact in India. NMJI (Natl Med J India). 2006;19(2):94.

30 Rao TS, Andrade C. Alcohol intake, morbidity, and mortality. Indian J Psychiatr. 2016;58(1):1.

31 Sinha K. More People Committing Suicide in South India: Report. The Times of India; 2008. Retrieved from http://timesofindia.indiatimes.com/articleshow/3842412.cms ?utm_source=contentofinterest\&utm_medium =text\&utm_campaign=cppst.

32 Dutta SS. Why Suicide Rates Are Higher in Tamil Nadu, Other Southern States in India. The New Indian Express; 2017. Retrieved from https://www.newindianexpress.com/n ation/2017/nov/16/why-suicide-rates-are-higher-in-tamil-nadu-other-southern -states-in-india-1702485.html.

33 Smith PC, Mossialos E, Leatherman S, Papanicolas I, eds. Performance Measurement for Health System Improvement: Experiences, Challenges and Prospects. Cambridge University Press; 2009.

34 Andhra Pradesh Is 3rd on Suicide List. Deccan Chronicle; 2018. Retrieved from https ://www.deccanchronicle.com/nation/current-affairs/210918/andhra-pradesh-is3rd-on-suicide-list.html.

35 AP Crime Rate Dips by 6 Per Cent in 2019. Business Standard; 2019. Retrieved from https://www.business-standard.com/article/pti-stories/ap-crime-rate-dips-by-6-percent-in-2019-119122900651_1.html.

36 National Crime Records Bureau. Crime in India. New Delhi: National Crime Records Bureau, Ministry of Home Affairs; 2016.

37 Soman CR, Safraj S, Kutty VR, Vijayakumar K, Ajayan K. Suicide in South India: a community-based study in Kerala. Indian J Psychiatr. 2009;51(4):261.

38 Sil A, Sil A, Dhillon P. Modeling determinants of deaths attributable to external causes among adults in India. Omega J Death Dying. 2021, 00302228211009736.

39 Schwarz F. Widening Educational Differentials in Mortality: Analysis for Austria with International Comparisons. 2005. VID Working paper 07/2005.

40 Kitagawa EM, Hauser PM. Differential Mortality in the United States. 2013. Harvard University Press. 